\title{
Influence of Building Information Modelling (BIM) on Engineering Contract Management in Nairobi, Kenya
}

\author{
Hellen Nyaboke Mosse ${ }^{1}$, Mugwima Njuguna², Charles Kabubo ${ }^{1}$ \\ ${ }^{1}$ Sustainable Materials Research \& Technology Centre (SMARTEC), Jomo Kenyatta University of Agriculture and Technology \\ (JKUAT), Nairobi, Kenya \\ ${ }^{2}$ Centre for Urban Studies, Jomo Kenyatta University of Agriculture and Technology (JKUAT), Nairobi, Kenya \\ Email: hellenmosse@gmail.com
}

How to cite this paper: Mosse, H.N., Njuguna, M. and Kabubo, C. (2020) Influence of Building Information Modelling (BIM) on Engineering Contract Management in Nairobi, Kenya. World Journal of Engineering and Technology, 8, 329-346. https://doi.org/10.4236/wjet.2020.83026

Received: June 2, 2020

Accepted: July 21, 2020

Published: July 24, 2020

Copyright $\odot 2020$ by author(s) and Scientific Research Publishing Inc. This work is licensed under the Creative Commons Attribution International License (CC BY 4.0).

http://creativecommons.org/licenses/by/4.0/

\begin{abstract}
Building Information Modelling (BIM) is a technology and a process that has brought changes in the construction's traditional procurement system. Kenya lacks contractual guidelines on implementation of BIM; this makes the adoption of BIM slow and difficult. Previous research has identified a gap in contractual relationships, roles and resulting risks. The objectives of this study were to investigate BIM adoption in Nairobi and to investigate the influence of BIM on Engineering Contract Management (ECM) in Nairobi Kenya. The survey research was a descriptive study with 175 responsive questionnaires. Respondents comprised of Civil Engineers, Construction Project Managers, Architects, Quantity Surveyors, Contractors and Facility Managers. Data was collected through self-administered questionnaire and in-depth interview. Descriptive analytics, correlation and Exploratory factor analysis methods were used to analyse quantitative data. Qualitative data was analysed thematically. It emerged that adoption level was at $56.6 \%$ and shallow understanding of BIM capabilities remains to be a barrier to its adoption and implementation. It also emerged that BIM improves ECM; when time, cost, quality, collaboration and return on investment improve, ECM becomes easier. Latent factors found in BIM and ECM relationship were Legal Implications, awareness and knowledge, efficiency, versatility, mandate and leadership, and competitiveness. Further, the study found out that BIM influence on ECM demands for establishment of standards, guidelines, policy, legal framework, and regulations, which can be achieved by amending the public procurement act which dictates the operation of all the other standard forms of contract. Further research should be conducted to measure whether the understanding of BIM had positively improved.
\end{abstract}




\section{Keywords}

Building Information Modelling, BIM, Adoption, Implementation, Collaboration, BIM Contractual Roles and Responsibilities, Contract Management

\section{Introduction}

One of the challenges in the construction industry is lack of effective collaboration which has contributed to poor quality delivery, time, and cost overruns in the lifecycle of a project. The BIM system gives the solution to these challenges caused by the Traditional procurement system. However, Kenya lacks a legal framework for BIM implementation, more so due to its collaborative nature that is changing relationships, roles, and responsibilities. The Kenyan industry lacks a formula, on how to handle these changes, how to use BIM, how to handle legal issues and how to handle contract management issues. The objectives of the study were to investigate BIM adoption, and to investigate the influence of BIM on engineering contract management (ECM) in Nairobi, Kenya.

The purpose of this survey study was to investigate how contract management has been affected by BIM which is relatively a new technology and whose adoption is ongoing, and whether it requires new systems and structures to be formed for maximum effectiveness and efficiency. The study facilitated understanding of the current standing of legal and contractual maturity of BIM. It was hoped the findings will stimulate the technological and legal fraternities to sufficiently deliberate the contractual uncertainties to facilitate a smoother uptake of BIM in the industry.

Research on BIM adoption, BIM's legal implications and contractual context for BIM has extensively been carried out in developed countries, the findings can be applied to most country scenarios. However, Bui et al., (2016) recommend comprehensive country specific research to be carried out in developing countries to address challenges being faced from the point of view of those countries.

\section{Literature Review}

\subsection{What BIM Is}

BIM is defined as a digital representation of the physical and functional characteristics of a facility, BIM is a shared knowledge resource for information about a facility, forming a reliable basis for decisions during its (facility) life-cycle; defined as existing from earliest conception to demolition [1]. Having several collaborators in the lifecycle of a project, makes management of information paramount [2]. BIM is not a software as has been the common misconception, rather, a Software supporting BIM should provide openness, interoperability, functionality, accuracy of data, expandability, time management, clash detection, cost estimation and facility management [3]. 
Building Information Modelling (BIM) is considered as a major paradigm shift after computer-aided design (CAD) by majority professionals and academic researchers [4]. Being a new technology, BIM system is a potential legal risk [5], that require contractual guidelines because new technologies affect the existing systems and structures, hence demanding for new laws and policy [6] to consolidate interrelationships and holistically, contract management [2].

According to [7] there are three BIM stages: stage 1 (object-based modelling), stage 2 (model-based collaboration), and stage 3 (network-based integration). Additionally, BIM is a collaboration tool with subsets referred to as dimensions (D): 3D (object modelling), 4D (time), 5D (cost), 6D (operations), 7D (sustainability) and even safety for $8 \mathrm{D}[8]$.

\subsection{Factors Guiding Adoption of BIM}

BIM is a tool used for lifecycle management of information [9], with the advantage of digital storing [10]. It promotes process cooperation, collaborative efforts with lifecycle seamless flow of information [11] [12]. It provides 3D visualization [13], with real-time characteristics that allow revision of drawings at any stage of construction [14]. Ability to cooperate with the entire team, including the contractor and facility manager who traditionally were late entrants [15]. Return on investment (ROI) has guided companies to implement BIM after studying projects done with BIM [16].

Benefits of BIM towards an effective ECM include, reduced delivery time, reduced project cost [16] [17] [18], resource saving, better coordination, detection of clashes, better time management [16] [18], improved profitability and customer-client relationship [2]. BIM makes decision management easier [19] and better project management [4]. It further enables effective risk management [15], conflict management [20], sustainability management and energy analysis which are all addressed collaboratively with interactive feedback on design decisions and consequences [9] [10].

Some professionals are more inclined to BIM more than others, for instance, Architects are taking the lead in BIM, but, Civil Engineers to have a lot to benefit from it, by using it on civil and infrastructure projects [14]. In Kenya, the private industry is leading in adoption, but it is also limited by the Public procurement Act which mainly favours the traditional procurement system.

\subsection{Conflict of the BIM System with the Traditional Procurement System}

Before Deficiencies of the traditional procurement methods include, time overrun, material wastage, cost overrun and quality compromise [21]. There is a conflict between BIM system and traditional system [13]; lifecycle collaborative BIM remains hindered by the adversarial nature of the traditional procurement system [5].

Legal issues brought by BIM include: Sharing of copyright data; model management and ownership; BIM standards; processes and responsibilities; standard 
of care and professional negligence; Intellectual Property Rights; professional liability; claims and disputes; BIM cost compensation; additional project insurance; collaborative working and new roles; software, data security and interoperability; admissibility of electronic-based documents; legal validation of design; legislation and judicial precedence [22] [23] [24].

Developing countries such as Kenya are generally struggling with lack of BIM awareness, lack of standard, little or no government support, unclear legal status of BIM, lack of skills, limited financial, unclear benefits of BIM [25], software, hardware and internet issues [26]. In Kenya, the private sector is leading adoption, though at a slow pace [27] [28].

The Kenyan Procurement Act may be a major legal impediment. The Public Procurement and Asset Disposal Act 2016 outlines that in case of conflict and inconsistencies with other standard documents, the Act is set to prevail, the only exception being where procurement of professional services is governed by an Act of Parliament.

\section{Methodology}

This was a descriptive study, through questionnaire survey and in-depth interview. Self-administered questionnaires with both structured and unstructured questions were used to collect data. In-depth interviews with knowledgeable persons were carried out using a pre-drafted interview guide. The research was done in Nairobi Kenya and the respondents were drawn from consultants in the construction industry, they included Civil Engineers, Construction Project Managers, Architects, Quantity Surveyors, Mechanical Engineers, Electrical Engineers, Contractors, and Facility Managers.

Respondents' selection was through stratified random sampling, but with a prerequisite of, awareness of BIM regardless of whether they had used it or adopted it. This measure was to help avoid training respondents who had never heard of BIM. Out of the 252 questionnaires distributed, 175 were completed and returned which accounted for $69 \%$ return rate. Considering that follow-up reminders were made resulting in improved return rate, there however, were respondents who still did not return their questionnaires, some cited that though they had heard of BIM, their competency could not afford them confidence to complete the questionnaire.

Knowledgeable persons on BIM subject were required for the in-depth interview, and therefore, Snowball sampling was used; 8 interviews were successfully conducted. The interview stopped at 8 respondents because saturation point had been reached [29]. Both the quantitative and qualitative data was cleaned, coded and analysed quantitatively and thematically respectively.

\section{Results}

The primary target of respondents comprised of eight groups but during data collection a third group emerged of 2 combined areas of practice namely, $0.6 \%$ 
Architect \& Contractor, 0.6\% Electrical Engineer \& Facility Manager, 1.1\% Construction Project Manager \& Contractor, 1.1\% Civil Engineer \& Construction Project Manager, 0.6\% Quantity Surveyor \& Facility Manager, 0.6\% Quantity Surveyor \& Contractor, 1.1\% Quantity Surveyor \& Construction Project Manager making a total of $6.3 \%$. See Table 1 for the profile of the respondents.

Respondents years of experience were: $36 \%$ had 0 - 5 years, 33.1\% had $6-10$ years, $16.6 \%$ had 11 - 15 years, and $14.3 \%$ had over 15 years of experience. Number of years that the respondents had used BIM were: $67.4 \%$ for $0-5$ years, $17.1 \%$ for 6 - 10 years, and 5.7\% for 11 - 15 years and 9.7\% had never used BIM. Respondents indicated their BIM roles as: 52\% were BIM user/modeler, $12 \%$ were BIM managers, $11.4 \%$ were BIM coordinators while $24.6 \%$ had no BIM roles.

The definition of BIM was provided, $96 \%$ agreed that it represented the definition of BIM. However, a contradiction arose on being asked if BIM is a software, $65.1 \%$ thought that BIM was a software, and only $32.6 \%$ thought BIM was not a software, whereas $2.3 \%$ did not know what to think. On adoption, $56.6 \%$ had adopted BIM, and $18.9 \%$ had not and $23.4 \%$ were planning to adopt, $1.1 \%$ were on ongoing adoption. $68 \%$ had a BIM manager, while $32 \%$ did not have a BIM manager. On the respondents who had used BIM on construction projects the study established that $68.6 \%$ had, $30.0 \%$ had not and $1.1 \%$ were unsure.

Respondents were also asked the stages of BIM they were in. $29.1 \%$ were in stage $0,28.6 \%$ were in stage $1,29.7 \%$ were in stage 2 , and $12.6 \%$ were in stage 3 . On BIM dimension the majority $71.4 \%$ mainly use BIM for 3D (modelling), $22.3 \%$ for $5 \mathrm{D}$ (cost), $16.6 \%$ 4D (time), 10.3\% 6D (operation), 9.7\% 7D (maintenance), and $8 \%$ used $8 \mathrm{D}$ (safety). Majority of respondents introduced BIM at $41.1 \%$ at design stage, $28.6 \%$ at preconstruction, $2.9 \%$ construction, $1.1 \%$ maintenance, $4.6 \%$ introduce BIM in all stages while $21.7 \%$ do not use BIM in any stage.

Table 1. Respondents profile, adoption rate per profession and overall adoption rate.

\begin{tabular}{cccccc}
\hline & Frequency & $\%$ & Cumulative $\%$ & $\begin{array}{c}\text { Adoption per } \\
\text { profession } \%\end{array}$ & $\begin{array}{c}\text { Overall } \\
\text { adoption \% }\end{array}$ \\
\hline Civil Engineer & 32 & 18.3 & 18.3 & 46.9 & 8.6 \\
Construction Project Manager & 37 & 21.1 & 39.4 & 59.5 & 12 \\
Architect & 37 & 21.1 & 60.6 & 70.3 & 14.9 \\
Quantity Surveyor & 31 & 17.7 & 78.3 & 38.7 & 6.9 \\
Mechanical Engineer & 6 & 3.4 & 81.7 & 66.7 & 2.3 \\
Electrical Engineer & 14 & 8.0 & 89.7 & 64.3 & 5.1 \\
Contractor & 3 & 1.7 & 91.4 & 100 & 1.7 \\
Facility Manager & 4 & 2.3 & 93.7 & 75 & 1.7 \\
Other (2 combinations) & 11 & 6.3 & 100 & 45.5 & 2.9 \\
Total & 175 & 100.0 & & & 56.6 \\
\hline
\end{tabular}


Adoption of BIM within each profession showed that Architects had the highest adoption rate at $70.3 \%$ while Quantity surveyors had the least at $38.7 \%$. In overall adoption rate Architects were leading at 14.9\% followed by Construction Project Managers at $12 \%$ and Civil engineers at $8.6 \%$ the bottom adopters were Facility Managers and Contractors who were both at $1.7 \%$. Refer to Table 1.

There were $29.1 \%$ with college BIM education though there lacks curriculum, those who had not received a BIM educated were $78.6 \%$. At the job market, $48 \%$ were self-trained and $20.6 \%$ were trained by the employer, some of whom were already self-trained. $14.3 \%$ were trained by software companies, $13.1 \%$ by software sellers, $9.1 \%$ by BIM champion, $2.9 \%$ by online tutorials, $1.1 \%$ in seminars and conferences, $1.7 \%$ were still on training while $8 \%$ were not trained.

Those who had not adopted BIM were asked what the reasons were, $17.7 \%$ reported that training was lacking, $12 \%$ said there was no client requirement, 9.7\% lack of standards \& guidelines, $9.1 \%$ said that BIM implementation process was too expensive, $8 \%$ cited lack of policy, $4.6 \%$ were satisfied with existing system, $4.6 \%$ did not understand BIM, $4 \%$ reported that BIM was too complicated and $0.6 \%$ cited that top management did not understand BIM.

The respondents were asked if traditional procurement system had failed the client. Majority agreed that it had failed the client; 54\% agreed, 29\% disagreed and $17 \%$ were uncertain. The preferred method of procurement were: Design-Bid-Build (DBB) was preferred by $39 \%$ followed by $26 \%$ Design-Build (DB), 22\% Management Contracting, 6\% Public-Private-Partnerships (PPP), 4\% Joint venture (JV) and 3\% did not have a preferred method of procurement. Respondents cited the following standard forms of contract commonly used in the Kenyan construction industry: The Joint Building Council (JBC) at $68.6 \%$, International Federation of Consulting Engineers (FIDIC) at 50.9\%, 4\% Public Procurement Regulatory Authority (PPRA formerly PPOA), 1.1\% Engineering Procurement and Construction Contract (EPC), 1.1\% The New Engineering Contract (NEC) and 0.6\% The Joint Contract Tribunal (JCT).

The question of whether BIM has influenced ECM, $72 \%$ of respondents stated it had, $5 \%$, disagreed while $23 \%$ were uncertain. BIM being a new technology had brought new roles, respondents identified them as BIM manager, BIM coordinator, BIM modeler/user, BIM consultant, and BIM champion.

\subsection{Reliability Test of the Likert Scale Items}

A reliability analysis to check internal consistency of the questionnaire's $75 \mathrm{Li}$ kert scale items was carried out; it was found to be excellent at a Cronbach's alpha of 0.963 .

\subsection{Correlation for BIM and ECM}

A correlation analysis was carried out using Pearson correlation $(r)$ to examine the relationship between the independent variable BIM and dependent variable 
ECM. The characteristics of BIM measured were collaboration, time saving, cost reduction, quality improvement, and ROI. Collaboration was found to be significant and positively correlated to ECM, $r(173)=0.453, p<0.01$. Time saving was positively correlated to ECM, $r(173)=0.439, p<0.01$. A complete list of correlations is shown in Table 2. Table 3 shows the correlation when BIM variables were combined to form one variable, BIM is significant and positively correlated to ECM, $r(173)=0.493, p<0.01$; When BIM improves ECM also improves in terms of time saving, cost reduction, quality improvement, better collaboration hence a positive ROI.

\subsection{Underlying Factors of Influence of BIM on ECM}

Exploratory factor analysis (EFA) was carried out with principal component analysis as the extraction method the primary purpose being to compute the latent factors of influence of BIM on ECM. This analysis used EFA because the number and nature of expected factors were unknown [30]. 5-point Likert scale was used to measure the 75 variables. The variables had a significant positive correlation at $p<0.01$ and $p<0.05$.

Kaiser-Meyer-Olkin (KMO) measure of sampling adequacy was found to be okay, at $\mathrm{KMO}=0.872$, Bartlett's test of sphericity was significant at $\chi^{2}=$ 9575.289, $p<0.001$. The diagonals of the anti-image correlation matrix were also over 0.5. Communalities were above 0.5 hence confirming that each item shared some common variance with other items. This proved that Factor analysis was a suitable method of analysis.

Table 2. Correlation for influence of BIM on ECM $(\mathrm{N}=175)$.

\begin{tabular}{|c|c|c|c|c|c|c|c|}
\hline & & $\mathrm{ECM}$ & $\mathrm{C}$ & TS & CR & QI & ROI \\
\hline ECM & $r$ & 1 & & & & & \\
\hline Collaboration (C) & $r$ & $0.453^{* *}$ & 1 & & & & \\
\hline Time saving (TS) & $r$ & $0.439^{* *}$ & $0.800^{* *}$ & 1 & & & \\
\hline Cost reduction (CR) & $r$ & $0.431^{* *}$ & $0.691^{* *}$ & $0.661^{* *}$ & 1 & & \\
\hline $\begin{array}{c}\text { Quality } \\
\text { improvement (QI) }\end{array}$ & $r$ & $0.376^{* *}$ & $0.690^{* *}$ & $0.659^{* *}$ & $0.667^{* *}$ & 1 & \\
\hline ROI & $r$ & $0.411^{* *}$ & $0.620^{* *}$ & $0.550^{* *}$ & $0.701^{* *}$ & $0.614^{* *}$ & 1 \\
\hline
\end{tabular}

**. Correlation is significant at the 0.01 level (2-tailed).

Table 3. Correlation for influence of BIM adoption on ECM ( $\mathrm{N}=175)$.

\begin{tabular}{cccc}
\hline & & ECM & BIM \\
\hline ECM & $r$ & 1 & \\
BIM & $r$ & $0.493^{* *}$ & 1 \\
\hline
\end{tabular}

**. Correlation is significant at the 0.01 level (2-tailed). 
A total of 75 variables were computed, $73.504 \%$ cumulative variance accounted for the 18 components with Eigenvalue greater than 1, as shown in $\mathrm{Ta}$ ble 4. A parallel analysis was then conducted, resulting in 7 factors retainment. The web engine parallel analysis calculates Eigenvalues based on parameters provided by the researcher, the result is compared with eigenvalue from computer generated data set, factors retained have a higher eigenvalue than that provided by corresponding eigenvalues from the engine [31]. See Table 5 for the summary.

The decision was made to conduct the test again with a preset fixed number of 7 factors. This resulted in 54.4\% cumulative variance being accounted for by preset factors. By Oblimin rotation the correlation of the 7 factors was below 0.5 implying they were not highly correlated, hence the need to change from oblique rotation to orthogonal rotation by varimax. The factor analysis was conducted again under varimax rotation.

Table 4. Total variance explained.

\begin{tabular}{|c|c|c|c|c|c|c|}
\hline \multirow{2}{*}{ Component } & \multicolumn{3}{|c|}{ Initial Eigenvalues } & \multicolumn{3}{|c|}{ Extraction Sums of Squared Loadings } \\
\hline & Total & $\%$ of Variance & Cumulative \% & Total & $\%$ of Variance & Cumulative \% \\
\hline 1 & 22.703 & 30.271 & 30.271 & 22.703 & 30.271 & 30.271 \\
\hline 2 & 4.626 & 6.168 & 36.439 & 4.626 & 6.168 & 36.439 \\
\hline 3 & 3.830 & 5.106 & 41.545 & 3.830 & 5.106 & 41.545 \\
\hline 4 & 3.314 & 4.419 & 45.964 & 3.314 & 4.419 & 45.964 \\
\hline 5 & 2.545 & 3.393 & 49.357 & 2.545 & 3.393 & 49.357 \\
\hline 6 & 2.075 & 2.766 & 52.123 & 2.075 & 2.766 & 52.123 \\
\hline 7 & 1.887 & 2.516 & 54.639 & 1.887 & 2.516 & 54.639 \\
\hline 8 & 1.618 & 2.157 & 56.796 & 1.618 & 2.157 & 56.796 \\
\hline 9 & 1.510 & 2.013 & 58.809 & 1.510 & 2.013 & 58.809 \\
\hline 10 & 1.462 & 1.949 & 60.759 & 1.462 & 1.949 & 60.759 \\
\hline 11 & 1.404 & 1.871 & 62.630 & 1.404 & 1.871 & 62.630 \\
\hline 12 & 1.310 & 1.746 & 64.377 & 1.310 & 1.746 & 64.377 \\
\hline 13 & 1.301 & 1.734 & 66.111 & 1.301 & 1.734 & 66.111 \\
\hline 14 & 1.240 & 1.653 & 67.763 & 1.240 & 1.653 & 67.763 \\
\hline 15 & 1.133 & 1.510 & 69.274 & 1.133 & 1.510 & 69.274 \\
\hline 16 & 1.091 & 1.455 & 70.729 & 1.091 & 1.455 & 70.729 \\
\hline 17 & 1.058 & 1.410 & 72.139 & 1.058 & 1.410 & 72.139 \\
\hline 18 & 1.024 & 1.365 & 73.504 & 1.024 & 1.365 & 73.504 \\
\hline 19 & .988 & 1.317 & 74.821 & & & \\
\hline 20 & .925 & 1.233 & 76.054 & & & \\
\hline $21-75$ & Omitted & by author & & & & \\
\hline
\end{tabular}

Extraction Method: Principal Component Analysis. 
Table 5. Parallel analysis tabulation with Calculated Eigenvalues.

\begin{tabular}{cccccc}
\hline $\begin{array}{c}\text { Component/ } \\
\text { factor }\end{array}$ & $\begin{array}{c}\text { Parallel } \\
\text { Eigenvalue }\end{array}$ & $\begin{array}{c}\text { Percentile } \\
\text { Eigenvalue }\end{array}$ & $\begin{array}{c}\text { Calculated } \\
\text { Eigenvalue }\end{array}$ & $\begin{array}{c}\% \text { of } \\
\text { variance }\end{array}$ & Decision \\
\hline 1 & 2.027918 & 2.109525 & 22.703 & 30.271 & Retain \\
2 & 1.944076 & 2.005931 & 4.626 & 6.168 & Retain \\
3 & 1.880338 & 1.925693 & 3.830 & 5.106 & Retain \\
4 & 1.827315 & 1.867672 & 3.314 & 4.419 & Retain \\
5 & 1.784450 & 1.826314 & 2.545 & 3.393 & Retain \\
6 & 1.740780 & 1.789314 & 2.075 & 2.766 & Retain \\
7 & 1.699345 & 1.736520 & 1.877 & 2.516 & Not retained \\
8 & 1.662571 & 1.694751 & 1.618 & 2.157 & Not retained \\
9 & 1.626509 & 1.655897 & 1.510 & 1.013 & Not retained \\
10 & 1.592867 & 1.630366 & 1.462 & 1.949 & Not retained \\
11 - 75 Omitted & $1.559097-$ & $1.594474-$ & $1.104-$ & $1.871-$ & Not retained \\
by author & 0.317981 & 0.342128 & 0.049 & 0.281 & \\
\hline
\end{tabular}

The internal consistency for the seventh factor was very poor but upon deleting two variables it improved to 0.592 . But having two variables in a factor did not seem to communicate a clear latent factor, this prompted another factor analysis to be run with fixed numbers of 6 factors instead of 7 .

The 6 factors retained were given umbrella names as follows. More details are tabulated in Appendix 1. Factor 1-Legal implications: Had 30.271\% variance explained, an Eigen value of 22.703, and it had 15 variables loading in it with a Cronbach Alpha of 0.933 inferring excellent reliability.

Factor 2-Awareness and Knowledge: Had 6.168\% variance explained, an Eigenvalue of 4.626, had 16 variables loading in it with a Cronbach Alpha of 0.939 inferring excellent reliability.

Factor 3-Efficiency: It had 5.106\% variance explained, an Eigenvalue of 3.830, 14 variables loaded in it with a Cronbach Alpha of 0.915 inferring excellent reliability.

Factor 4-Versatility: Had 4.419\% variance explained, an Eigenvalue of 3.314, 11 variables loaded in it with a Cronbach Alpha of 0.889 inferring high reliability.

Factor 5-Mandate and leadership: Had 3.393\% variance explained, an Eigenvalue of 2.546, with 12 variables, Cronbach Alpha of 0.831 inferring high reliability.

Factor 6-Competitiveness: $2.766 \%$ variance explained, an Eigenvalue of 2.075, loaded 6 variables with a Cronbach Alpha of 0.671 inferring moderate reliability.

\subsection{Situation of BIM Adoption in Nairobi, Kenya}

The in-depth interview showed that BIM adoption in Kenya is still low, due to shallow understanding of BIM, this argument was based on observations made 
by the respondents from their interactions in the construction industry. The descriptive statistics showed the adoption rate of $56.6 \%$, it also showed that though $96 \%$ of the respondents knew what BIM is, only $33 \%$ rightfully stated it is not a software, $65 \%$ believed that BIM is a software and the remaining $2 \%$ did not know whether it is a software or not. A cross-tabulation of this contradiction is shown in Table 6, where 62.6\% of those who have adopted BIM believed BIM is a software the trend is similar for the non-adopters, those planning to adopt and those who had partially adopted. The low level of adoption was because of high cost of implementation, lack of proper training, lack of awareness and knowledge, lack of contractual guidance, lack of necessary skills, change resistant attitude, and lack of understanding. Other factors include, Education curriculum failure to include BIM, complexity of BIM, lack of leadership, inadequate sensitization, size of projects dictating adoption, lack of case studies and lack of BIM champions. Further, Contractors unwillingness to adopt, client's failure to require BIM, inflexible employers, unfavourable procurement rules, rigid traditional procurement system and lack of government mandate are other reasons for low adoption level. These low numbers contribute to difficulty in collaboration.

Respondents opined that BIM complements professional work, other benefits include, time and cost saving, generative designs, and real-life simulation. Complex projects design can be handled without having to expand the workforce. Additionally, lifecycle information storage and management make operation and maintenance easier and cost effective.

According to the respondents, BIM has influenced contract management by making it easier. Additionally, BIM facilitates, collaboration, improved quality, business benefit, positive ROI, easier decision making, clash detection, early problem detection in professional relationships. It also makes it easier for parties to appreciate design components, reduces adversarial relationships, it eliminates inconsistencies and abortive works. Bills of quantities are more accurately done, it gives transparency, empowers clients to appreciate real-time 3D visualization. It thus enables risk management through early identification and mitigation. There is emergence of new roles such as BIM manager, BIM coordinator and BIM Consultant.

Table 6. Cross-tabulation of BIM adoption and whether BIM is a software.

\begin{tabular}{cccccc}
\hline & & \multicolumn{4}{c}{ Is BIM a software } \\
\cline { 3 - 6 } & & Yes & No & I do not know & Total \\
\hline \multirow{2}{*}{$\begin{array}{c}\text { Have you } \\
\text { adopted BIM } \\
\begin{array}{c}\text { in your } \\
\text { organization }\end{array}\end{array}$} & Yes & $62.6 \%$ & $36.4 \%$ & $1.0 \%$ & $100 \%-99$ No. \\
& Po & $63.6 \%$ & $27.3 \%$ & $9.1 \%$ & $100 \%-33$ No. \\
& Partially/ongoing adoption & $100 \%$ & $0 \%$ & $0 \%$ & $100 \%-2$ No. \\
& Total & $70.7 \%$ & $29.3 \%$ & $0.0 \%$ & $100 \%-41$ No. \\
& & $65.1 \%$ & $32.6 \%$ & $2.3 \%$ & $100 \%-175$ No. \\
\hline
\end{tabular}




\section{Discussion}

From the results of the research, the BIM adoption level in Nairobi was established as 56.6\%, with Architects, Construction project managers and Civil engineers in that order leading in adoption, designers such as Engineers and architects are more receptive of BIM as compared to other groups. Lack of understanding is the biggest impediment to BIM adoption and even though $96 \%$ of the respondents seemingly knew what BIM was, $65.1 \%$ thought that BIM is a software which is not the case; only $32.6 \%$ knew that it is not a software. Despite BIM having many dimensions, 3D modelling was largely utilized, other dimensions remained unexplored. Kenyan research and educational centres are failing by not including BIM in the curriculum, this affects the technical capacity that could be used to advance skills in the job market.

When BIM and ECM were correlated, the correlation was significant and positive. That means that, when BIM adoption improves, ECM also improves hence project's success. When the adoption increases, the effect on ECM becomes more pronounced. This influence could be interpreted through the six underlying factors on the relationship between BIM and ECM, namely: Legal implications, awareness and knowledge, efficiency, versatility, mandate and leadership, and competitiveness. Refer to Appendix 1. The factors have been interpreted as below.

Legal risks: 15 variables loaded under this factor, data security loaded highest and contractual guidelines loaded the least. BIM operates in a digital environment unlike the traditional system that operates with hardcopy documentation, security of data thus becomes an immediate concern as people implement BIM. Processes need to be revised, responsibility and liability should be assigned to the right professionals, which should include the new skills brought by BIM. Legislation and legal precedence rated the fourth highest; being a new system in Kenya, BIM lacks judicial precedence, hence the need for laws to enable effective ECM. Data interoperability was an implication because consultants use different types of software and require collaborating digitally. Sharing of copyright data and intellectual property rights have a very thin line in the digital BIM. The implementation process comes with a cost implication, ways of recovering the cost incurred were unclear. Further, BIM environment is transparent with each design component meaning something to a professional, so standard of care becomes a collective responsibility, professional negligence is reduced, and admissibility of electronic-based document is managed by the BIM manager. Currently, there lacks standards to oversee this, but with formulation of standards it will make model management easier. Legal validation of design by the local authority needs to consider using the digital model unlike the traditional system that uses hardcopies and, in some cases, 2D digital drawings. Condition of contracts needs revision from traditional hardcopy system to digital BIM system.

Awareness and knowledge: 16 variables loaded under this factor, dispute resolution loaded highest and clash detection loaded the least. Being aware and having knowledge of BIM through education and training, followed by proper 
use of the BIM system makes ECM easier. Dispute resolution loaded highest, then, improved workmanship, reduced variations and claims, improved quality, decision management and communication are made easier through its collaborative nature. BIM also facilitates positive ROI, reduced cost of the project, early problem detection, real-time correction of information at any stage, effective coordination, reduced cost of operation and maintenance, faster execution of a project and clash detection.

Efficiency: 14 variables loaded under efficiency with better coordination loading the highest and BIM definition the least. The benefits of BIM make ECM easier and enable efficiency in projects through, better coordination, collaboration, clash detection, improved accuracy, time saving, improved communication, buildability, intelligent $3 \mathrm{D}$ visualization, cost saving, real-time capabilities, better decision management, transparency and quality improvement. BIM definition variable defines BIM and depicts the influence of efficiency on ECM.

Versatility: 11 variables loaded under versatility, safety management loaded highest and consistent lifecycle information loaded the least. BIM brings versatility to ECM, coordination of those aspects of a construction project that were traditionally separate from design, are centrally managed. For instance, Safety management is a major concern in construction sites, BIM real-time monitoring, evaluation and analysis ensures mitigation measures are put in place in time, this applies to risk management in general. Further, positive ROI realized by professionals and clients, leads to, improved customer client relationship. Other aspects are improved facility management, sustainability, and energy analysis. Ensuring consistent lifecycle information hence making ECM easier.

Mandate and leadership: 12 variables loaded under this factor, the government should adopt their procurement process to suit collaborative BIM loaded highest and written materials to guide BIM implementation loaded the least. When it comes to new technologies the authorities become vital in enabling countrywide implementation. Legal validation of the digital model to the Nairobi County Council can only function through a mandate. The government may need to make BIM implementation compulsory, hence requiring revised or new sets of standard forms of contract. The mandate will ensure Kenyan consultants are equally competitive as their international counterparts towards winning construction contracts. A regulatory body mandated by the government is important to help with standardization of BIM within the country. The government should also mandate the digital BIM model to be recognized as a contract document. Case studies on BIM projects and noteworthy BIM publications in Kenya, will be important in guiding stakeholders in BIM adoption hence abandon the traditional procurement system which is not receptive to technological advancement.

Competitiveness: 6 variables loaded under competitiveness with my organization needing standards and guidelines loading the highest and size of the project loading the least. An organization having standards and guidelines on BIM and engaging a BIM consultant is a good indicator of international compe- 
titiveness in ECM. Pressure to remain competitive shows that progressive trends are themselves full of pressure to stay at the top. Additionally, the necessary technological tools must be put in place. The bigger the project the more the need to implement BIM, smaller projects seem not to be presenting contract management challenges.

\section{Conclusions}

Definition of influence in the context of this paper is to have an effect or change on how something develops or behaves. BIM adoption and implementation have an effect on the development of ECM in response. Legal implications call for a legal framework purposely for the BIM system. There is a need for increased awareness and knowledge whereby perception and understanding of BIM and its benefits make contract management easier, reducing risks, improving relationships, saving resources, and giving business benefits. Components of BIM regarded to be important for its adoption are increasing efficiency in ECM. Versatility of BIM capabilities bring more advantages beyond the primary ones depicted by efficiency factor. Further, new relationships will be created such as contractor's and facility manager's early involvement in the project, inevitably, novel risks ensue, that require a BIM system solution and not a solution from the traditional system.

The government and its agencies have a responsibility to revise the Kenyan procurement ACT to suit collaborative BIM. International competitiveness requires that professionals use the most efficient tools to sell their engineering creativity, this competitiveness package enables projects success. BIM is slowly but aggressively demanding for standards, guidelines, policy, legal framework, and regulations, this will improve contractual relationships and give contractual guidelines on roles, relationships, and risks. Ultimately this will enable effective ECM.

Adoption and implementation of BIM requires awareness of what BIM is, leadership to give guidance, education to build technical capacity, training to advance the skills and necessary technology to execute the BIM process. There is generally low understanding of BIM in Nairobi; therefore, the players in the construction industry should make understanding of BIM an urgent pull factor towards efficient and effective ECM. Future studies should find out if this state is changing.

\section{Acknowledgements}

The authors thank all respondents for making this research successful.

\section{Conflicts of Interest}

The authors declare no conflicts of interest regarding the publication of this paper.

\section{References}

[1] National Institute of Building Science United States (2019) Frequently Asked Questions about National BIM Standard-United States. 
https://www.nationalbimstandard.org/faqs

[2] Azhar, S., Khalfan, M. and Maqsood, T. (2012) Status of BIM Adoption and the BIM Experience of Cost Consultants in Australia. Australasian Journal of Construction Economics and Building, 12, 15-28. https://doi.org/10.5130/AJCEB.v12i4.3032

[3] Bouška, R. (2016) Evaluation of Maturity of BIM Tools across Different Software Platforms. Procedia Engineering, 164, 481-486. https://doi.org/10.1016/j.proeng.2016.11.648

[4] Kalinichuk, S. (2015) Building Information Modeling. Journal of Systems Integration, 3, 25-34. https://doi.org/10.20470/jsi.v6i3.235

[5] Kuiper, I. and Dominik, H. (2013) Rethinking the Contractual Context for Building Information Modelling (BIM) in the Australian Built Environment Industry. Australasian Journal of Construction Economics and Building, 13, 1-17. https://doi.org/10.5130/AJCEB.v13i4.3630

[6] Mouzas, S. and Blois, K. (2007) Relational Contract Theory: Confirmations and Contradictions.

[7] Succar, B. (2009) Building Information Modelling Framework: A Research and Delivery Foundation for Industry Stakeholders. Automation in Construction, 18, 357-375. https://doi.org/10.1016/j.autcon.2008.10.003

[8] Smith, P. (2014) Project Cost Management with 5D BIM. Procedia Social and Behavioral Sciences, 119, 475-484. https://doi.org/10.1016/j.sbspro.2014.03.053

[9] Xu, X., Ma, L. and Ding, L. (2014) A Framework for BIM-Enabled Life-Cycle Information Management of Construction Project. International Journal of Advanced Robotic Systems, 11, 1-13. https://doi.org/10.5772/58445

[10] Nowak, P., Ksiązek, M., Draps, M. and Zawistowski, J. (2016) Decision Making with Use of Building Information Modeling. Procedia Engineering, 153, 519-526. https://doi.org/10.1016/j.proeng.2016.08.177

[11] Grzyl, B., Miszewska-Urbańska, E. and Apollo, M. (2017) Building Information Modelling as an Opportunity and Risk for Stakeholders Involved in Construction Investment Process. Procedia Engineering, 196, 1026-1033. https://doi.org/10.1016/j.proeng.2017.08.045

[12] Nicał, A.K. and Wodyński, W. (2016) Enhancing Facility Management through BIM 6D. Procedia Engineering, 164, 299-306. https://doi.org/10.1016/j.proeng.2016.11.623

[13] Bosch-Sijtsema, P. and Gluch, P. (2019) Challenging Construction Project Management Institutions: The Role and Agency of BIM Actors. International Journal of Construction Management, 1-11. https://doi.org/10.1080/15623599.2019.1602585

[14] Ali, A. (2016) Building Information Modelling (BIM) and Project Management Implementation in Infrastructure and Civil Construction.

[15] Olsen, D. and Taylor, J.M. (2017) Quantity Take-Off Using Building Information Modeling (BIM), and Its Limiting Factors. Procedia Engineering, 196, 1098-1105. https://doi.org/10.1016/j.proeng.2017.08.067

[16] Khodeir, L.M. and Nessim, A.A. (2016) BIM2BEM Integrated Approach: Examining Status of the Adoption of Building Information Modelling and Building Energy Models in Egyptian Architectural Firms. Ain Shams Engineering Journal, 1-10.

[17] Aziz, N.D., Nawawi, A.H. and Ariff, N.R.M. (2016) Building Information Modelling (BIM) in Facilities Management: Opportunities to Be Considered by Facility Managers. Procedia-Social and Behavioral Sciences, 234, 353-362.

https://doi.org/10.1016/j.sbspro.2016.10.252 
[18] Azhar, N., Kang, Y. and Ahmad, I.U. (2014) Factors Influencing Integrated Project Delivery in Publicly Owned Construction Projects: An Information Modelling Perspective. Procedia Engineering, 77, 213-221. https://doi.org/10.1016/j.proeng.2014.07.019

[19] Yalcinkaya, M. and Arditi, D. (2013) Building Information Modeling (BIM) and the Construction Management Body of Knowledge. 10th Product Lifecycle Management for Society (PLM), Nantes, 6-10 July 2013, 619-629. https://doi.org/10.1007/978-3-642-41501-2_61

[20] Charehzehi, A., Chai, C., Yusof, A.M., Chong, H. and Loo, S.C. (2017) Building Information Modeling in Construction Conflict Management. International Journal of Engineering Business Management, 9, 1-18. https://doi.org/10.1177/1847979017746257

[21] Borjeghaleh, R.M. and Sardrou, J.M. (2016) Approaching Industrialization of Buildings and Integrated Construction Using Building Information Modeling. Procedia Engineering, 164, 534-541. https://doi.org/10.1016/j.proeng.2016.11.655

[22] Arshad, M.F., Thaheem, M.J., Nasir, A.R. and Malik, M.S.A. (2019) Contractual Risks of Building Information Modeling: Toward a Standardized Legal Framework for Design-Bid-Build Projects Standardized Legal Framework for Design-Bid-Build Projects. Journal of Construction Engineering and Management, 145, 1-14. https://doi.org/10.1061/(ASCE)CO.1943-7862.0001617

[23] Manderson, A., Jefferies, M. and Brewer, G. (2015) Building Information Modelling and Standardised Construction Contracts: A Content Analysis of the GC21 Contract. Construction Economics and Building, 15, 72-84. https://doi.org/10.5130/AJCEB.v15i3.4608

[24] Eadie, R., McLernon, T. and Patton, A. (2015) An Investigation into the Legal Issues Relating to Building Information Modelling (BIM). RICS COBRA AUBEA 2015, Sydney, 8-10 July 2015, p. 8.

[25] Bui, N., Merschbrock, C. and Munkvold, B.E. (2016) A Review of Building Information Modelling for Construction in Developing Countries. Procedia Engineering, 164, 487-494. https://doi.org/10.1016/j.proeng.2016.11.649

[26] Hosseini, M.R., Azari, E., Tivendale, L., Banihashemi, S. and Chileshe, N. (2016) Building Information Modeling (BIM) in Iran: An Exploratory Study. Journal of Engineering, Project, and Production Management, 6, 78-89. https://doi.org/10.32738/JEPPM.201607.0002

[27] Manza, D. (2016) Influence of Building Information Modelling Adoption on Completion of Construction Projects: A Case of Nairobi County, Kenya. Published Master's Thesis, University of Nairobi, Nairobi.

[28] Musyimi, M.M. (2016) Building Information Modelling Adoption in Construction Project Management in Kenya: A Case Study of Nairobi County. Published Master's Thesis, University of Nairobi, Nairobi.

[29] Hennink, M.M., Kaiser, B.N. and Marconi, V.C. (2017) Code Saturation versus Meaning Saturation: How Many Interviews Are Enough. Qualitative Health Research, 27, 591-608. https://doi.org/10.1177/1049732316665344

[30] Williams, B., Onsman, A. and Brown, T. (2010) Exploratory Factor Analysis: A Five-Step Guide for Novices. Journal of Emergency Primary Health Care, 8, 1-13. https://doi.org/10.33151/ajp.8.3.93

[31] Patil, V.H., Singh, S.N., Mishra, S. and Donovan, T. (2017) Parallel Analysis Engine. Patil 2017 Parallel Analysis. https://analytics.gonzaga.edu/parallelengine 


\section{Appendix 1. Influence of BIM on ECM Summary Table}

\begin{tabular}{l} 
Factor \\
\hline \\
\\
Factor 1: \\
Legal implications \\
variance explained $=$ \\
$30.271 \%$ \\
Eigenvalue $=22.703$ \\
Cronbach's Alpha $=$ \\
0.933 \\
$\mathrm{~N}=15$
\end{tabular}

Variable
Data security

Loading factor

Processes and responsibilities 0.759

Professional liability

Legislation and judicial precedence

Data interoperability

Sharing of copyright data

0.694

Intellectual Property Rights

0.691

Cost compensation

0.672

Standard of care and professional negligence

0.663

Admissibility of electronic-based document

0.660

Lack of BIM standards

0.654

Model management

0.632

legal validation of design (NCC submissions)

0.582

Condition of contracts (e.g. FIDIC)

0.532

It is necessary to have contractual guidelines to guide in BIM adoption

BIM makes dispute resolution easier

0.736

BIM improved good working relationship

0.724

BIM helps to reduce variations

0.701

BIM improves quality

0.687

BIM improves decision management process

0.686

BIM improves communication in the construction team

0.680

Factor 2:

BIM facilitates positive ROI

0.663

Awareness and

knowledge variance

BIM helps to reduce claims

0.654

explained $=6.168 \%$

Eigen value $=4.626$

Cronbach's Alpha =

0.939

$\mathrm{N}=16$

BIM reduces cost of a project

0.646

BIM aids in early problem detection

0.626

BIM makes real time correction of information easy at any stage of a project

0.620

BIM facilitates effective coordination

0.615

BIM reduces cost of operation and maintenance of a facility

BIM enables the construction Team to work together effectively and efficiently

BIM enables faster execution of a project hence saving time

0.560

BIM aids in clash detection of construction element as designed by different professionals 


\section{Continued}

\begin{tabular}{l}
\hline \\
Factor 3: \\
Efficiency variance \\
explained = 5.106\% \\
Eigenvalue = 3.830 \\
Cronbach's Alpha = \\
0.915 \\
$\mathrm{~N}=14$
\end{tabular}

Factor 4:

Versatility

Better coordination - BIM component

0.731

Collaboration - BIM component

0.705

Clash detection - BIM component

0.675

Improved accuracy - BIM component

0.630

Time saving - BIM component

0.628

improved communication - BIM component

0.609

Buildability - BIM component

0.609

Intelligent $3 \mathrm{D}$ visualization - BIM component

0.578

Cost saving - BIM component

0.557

Realtime capabilities - BIM component

0.554

Better decision management - BIM component

0.547

Transparency - BIM component

0.529

Quality improvement - BIM component

0.499

BIM definition

0.484

Safety management

0.644

Improved facility management

0.617

Return on investment

Risk management

0.593

variance explained $=$

Improved customer client relationship

0.582

4.419\%

Sustainability

0.572

Eigenvalue $=3.314$

Financial cost

0.544

0.889

$\mathrm{N}=11$

Top management support

Energy analysis

0.498

Technological capabilities

Consistent lifecycle information

0.390

Government should adopt their procurement processes to suit collaborative BIM

0.671

NCC submissions may require BIM model in future

Government need to make BIM implementation compulsory

0.609

BIM requires a new set of standards forms of contract

Factor 5:

Existing forms of contract should be modified to suit BIM

Mandate and leadership variance explained $=$

Construction contracts are competitively awarded to both local and

international firms depending on BIM capabilities

Eigenvalue $=2.546$

Cronbach's Alpha $=$

There is need for regulatory body mandated by the government

0.831

$\mathrm{N}=12$

The digital BIM model should be recognized as a contract document

There are case studies done on BIM projects in Kenya

The traditional procurement has failed to meet client's expectations

Stakeholders are willing to pioneer in BIM adoption

There are written materials to guide BIM implementation 


\section{Continued}

My organization has standards and guidelines on BIM adoption

Factor 6:

Competitiveness

variance explained $=$

$2.766 \%$

My organization has engaged a BIM consultant to help in BIM adoption

Eigen value $=2.075$

Cronbach's Alpha $=$

0.671

$\mathrm{N}=6$

Pressure to remain competitive - BIM component

BIM has influenced/impacted engineering contract management

BIM hardware must be recommended by the type of software in use

$\mathrm{KMO}=0.872$, Bartlett's $\chi^{2}=9575.289, p<0.001$, Extraction Method: Principal Component Analysis. Rotation Method: Varimax with Kaiser Normalization. a. Rotation converged in 8 iterations. 